\title{
The Business Behavior Model: A Revised Version
}

\author{
Noelia Palomares ${ }^{1}$ and Birger Andersson ${ }^{2}$ \\ ${ }^{1}$ Valencia University of Technology, Department of Information Systems and Computation \\ Camí de Vera s/n, 46071 Valencia, Spain \\ noepabo@posgrado.upv.es \\ ${ }^{2}$ Stockholm University, Department of Computer and System Sciences \\ SE-164 40 Kista, Sweden \\ ba@dsv.su.se
}

\begin{abstract}
The problem of aligning the strategy of an enterprise and supporting IT resources has been recognized since decades. In this paper we revise a model - The Business Behavior Model (BBM) - which is envisioned to help in the alignment between the goal layer and the business layer of an enterprise. A number of problems are identified in the original BBM and solutions for those problems are proposed. A short illustrative case is provided that shows the applicability of the revised BBM.
\end{abstract}

\section{Introduction}

The problem of aligning the strategy of an enterprise and supporting IT resources has been recognized since decades [1]. The common understanding is that once a strategy is made explicit then, somehow, available IT resources should be configured to provide maximum support for the strategy [2]. Instrumental for this work has been the use of models. Strategy has been captured or made explicit in Goal models [3, 4, 5] and IT resources have been captured through Data or Process models $[6,7,8]$ in an operational layer.

One way to achieve alignment then has been through the application of rules and use of patterns $[9,10]$. The introduction of a new strategy in a goal model results in a selection of a pattern that when applied changes e.g. a process model in a well defined way. For example, the formulation of the goal "I need to increase production $10 \%$ the coming six months" can result in introduction of new actors and support systems in a process model.

It has been argued that the gap between the strategy level and the operational level is too large to effectively achieve business and IT alignment as alluded to above [11]. To decrease this gap a business layer was introduced between them. The layers reflect a separation of concerns:

- Goal layer. The goal layer is described by means of goal models. Goal models are used in the earliest phases of business and information systems design, where they help in clarifying interests, intentions, and strategies of different stakeholders answering to the "why" of the business;

- Business layer. The business layer is described by means of business models [12, 13, 14]. Business models give a high level view of the activities taking place in and 
between organizations by identifying agents, resources, and the exchange of resources between the agents. So, a business model focuses on the "what" of a business;

- Process layer. The process layer is described by means of data and process models. Process models focus on the "how" of a business, as they deal with operational and procedural aspects of business communication, including control flow, data flow and message passing.

The focus of this paper is on the alignment between the goal layer and the business layer. In particular, we want to investigate the Business Behavior Model (BBM) [15, 16] that was conceived as a model that complements traditional models and methods for alignment, e.g. $[1,17,18]$. The main feature of the BBM is that it is deliberately designed to contain concepts that is normally thought of as belonging to different modeling layers (in the case of BBM both the goal layer and business layer). As far as we are aware there has been no attempt at this approach when trying to align goal and business layers. The design was motivated by the sometimes poor results achieved when working in the traditional ways [16]. While investigating the BBM a number of unclear or problematic points were discovered. The purpose of this paper is to point at those problems and discuss some solutions. By strengthening the BBM it is envisioned that it will become a useful and valuable tool for business/IT-alignment.

The rest of the paper is structured as follows: in section 2 we describe the original BBM and its theoretical foundations. Section 3 defines and explains important modifications done to the original BBM. Section 4 contains an illustrative example to show how to use the model; and finally, section 5 contains a concluding discussion and directions for future research.

\section{Theoretical Backgrounds for the BBM}

In this section we briefly overview the theoretical foundations for the Business Behaviour Model.

The Rational Agent Theory [19] describes how agents can reach their intentions by means of decisions. Agents are considered rational and are represented as having mental attitudes like beliefs, desires, and intentions (BDI). Based on its beliefs the agent constructs a set of desires from which it deliberately and rationally selects one. The selected one becomes its intention. This way of describing an agent lies at the heart of the BBM.

The Resource-Based View (RBV) [20] is a business management tool able to determine what resources are strategic for an organization. A resource is strategic when it fulfills a set of criteria. The VRIN (Value, Rareness, Inimitability, and Nonsubstitutability) framework is a commonly used set of criteria proposed by Barney [21]. In the BBM the way for a rational agent to fulfill its intentions is through exchange of resources with its environment.

The Business Model Ontology (BMO) [12, 22] describes the business model of a firm. As a minimum a business model has to address the following four perspectives: Product and Service: what an agent offers; Client: who the agent's envisioned customers are; Activity: who the agent's envisioned partners are; Financial: the costs and revenues associated with the offering. The perspectives proposed in BMO are reflected in the way resources are analysed in BBM. 
Causal graphs [23] are directed acyclic graphs, in which nodes denote variables features of a system and arcs denote direct causal relations between these features. The Causal graph constitutes the basis for the syntax of the BBM. The basic concepts of the causal graph are summarized in table 1:

Table 1. Basic concepts of causal graph [15, 23]

\begin{tabular}{|c|c|}
\hline Nodes & Arcs \\
\hline $\begin{array}{l}\text { Chance: A variable that could conditionally } \\
\text { be influenced by other nodes. }\end{array}$ & $\begin{array}{l}\text { Informational: The out-node is considered before } \\
\text { the in-node is analyzed. }\end{array}$ \\
\hline $\begin{array}{l}\text { Utility: The expected utility of the outcome } \\
\text { from decisions nodes. }\end{array}$ & $\begin{array}{l}\text { Causal: The in-node has conditional probability to } \\
\text { take a certain value considering a previous out- } \\
\text { node. }\end{array}$ \\
\hline $\begin{array}{l}\text { Decision: The alternatives that are possible } \\
\text { considering the studied domain. }\end{array}$ & $\begin{array}{l}\text { Definitional: The in-node is composed of the all } \\
\text { nodes linked to it. }\end{array}$ \\
\hline
\end{tabular}

\subsection{The Original BBM}

The BBM is a model which describes the impact of the participation of agents in a business by integrating their resources in a causal graph. The participation is realized through decisions and driven by motivations [15]. Figure 1 shows the initial proposal.

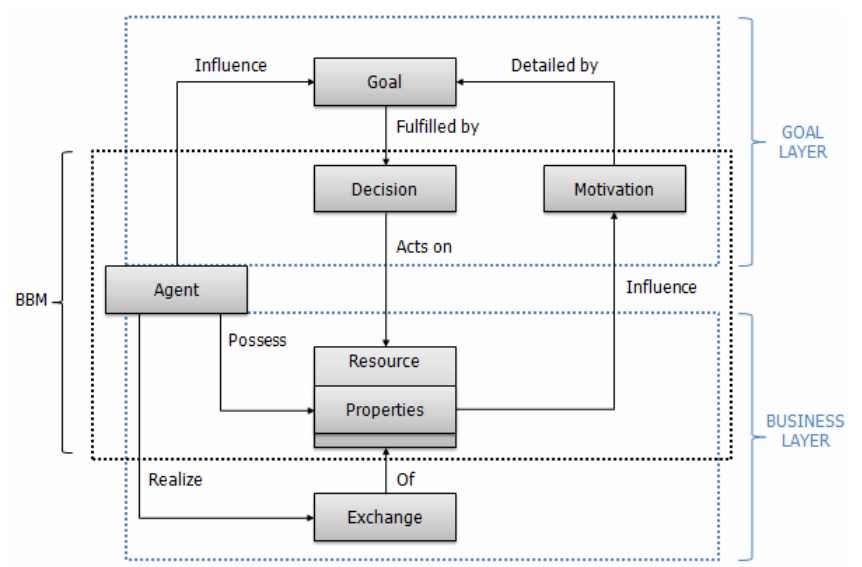

Fig. 1. The main concepts and position of the BBM [15]

According to figure 1, the BBM was developed as an intermediate model between the strategic layer and the business layer by simultaneously incorporating notions of goal models and value models.

The BBM has two parts - the modeling formalism and a methodology for applying it. Firstly, the modeling formalism contains agents, decisions, motivations, resources (with properties), and relations between those concepts. Secondly, using the BBM for 
alignment work means to use it systematically. This is done either by constructing a $\mathrm{BBM}$ on the basis existing goal or business models, or vice versa (i.e., constructing goal or business models based on an existing BBM). In order to do this a modeler must find correspondences between the notions of those models and the concepts of the BBM. As a result of semantic analyses correspondences between concepts of the BBM and several goal and business models are presented in table 2. Table 2 contains in part results of previous work presented in [15].

\subsection{Problems in the Original BBM}

We have found several problems related to the layer positioning of the concepts, syntax, semantics, and methodology in the original BBM proposal.

For the positioning of the concepts (according to figure 1); on one hand, the strategic layer contains goals, decisions and motivations. On the other hand, the business layer contains resources (with properties) and exchanges of resources. The original positioning of decisions in the goal layer is problematic. To ease the analysis we now position decision between the goal layer and the business layer together with agent. Based on what goals exist in the goal layer an agent takes a decision that affects the resource exchanges in the business layer. In other words, an agent that takes decisions conceptually becomes the "bridge" between the layers. An added benefit is that the separation of concerns between the layers is mostly maintained.

For the syntax, the original version presented graphical notation just for the following nodes: economic resources, economic resources properties, non-economic resources, and decisions. However, agents were not explicitly included and motivations were not precisely observable in the language - a motivation was modeled trough the improvement (increase or decrease) of non-economic resources by means of value indicators on causal links. Agents are now included giving the possibility to model external agents with whom the principal agent exchange resources with. In the original BBM motivations were treated as synonyms of non-economic resources. This was problematic as one can argue that an agent can have as a motivation to create a noneconomic resource (e.g., some skill). Added symbols for motivations have been added to capture this.

Regarding links, the original version included informational links, causal links (using value indicators), definitional links, creational links, XOR-relation, and ANDrelation. We found it problematic to handle value indicators of the causal links which could take two values indicating strong or light impact $(++,+,-,--)$. But it is quite hard to discern between strong or light so we now use a one level scale - positive or negative impact. We have also added a new type of link which we call a suppressing link. It is represented using the same symbol that it is used to represent creational links. The reason for adding it is to be able to capture that a motivation can result in a decision to delete a resource in a business model. This was not possible to express in the original BBM.

For the semantics, we added definitions for new concepts (agent and motivation) and clarified other definitions. The first point is about resources. In the original BBM, there were different types of resources: economic and non-economic ones. Economic resources were defined by at least one property. A property was composed of a name, 
a scale, and a value where properties always had a positive value on their scales. We specify the differences between both types of resources - above all the operations that are permitted depending on the type. For example, economic resources can be exchanged but non-economic resources cannot. We establish a criterion to be able to tell the difference between an economic resource and a property, and include negative value on the property scales. The other points relates to decisions and motivations.

Finally, it was necessary to change the original methodology because of inclusion of new elements and altered definitions.

\section{Improvement of the Business Behavior Model}

Meta-model, Syntax, and Semantics. The meta-model for the original BBM is changed and figure 2 shows the new proposal. A model is built from one agent's (called 'the principal agent') point of view. The model is a scenario where an agent's motivations are represented. Motivations can be fulfilled in several ways; by obtaining a certain resource, either economic resources (new ones can be introduced or deleted by taking decisions), or non-economic resources (which are created, e.g. a 'skill'). Economic resources are defined by their properties. A value of a property can positively or negatively affect other properties. The ways by which motivations are fulfilled are represented as hierarchies or sequences of decisions.

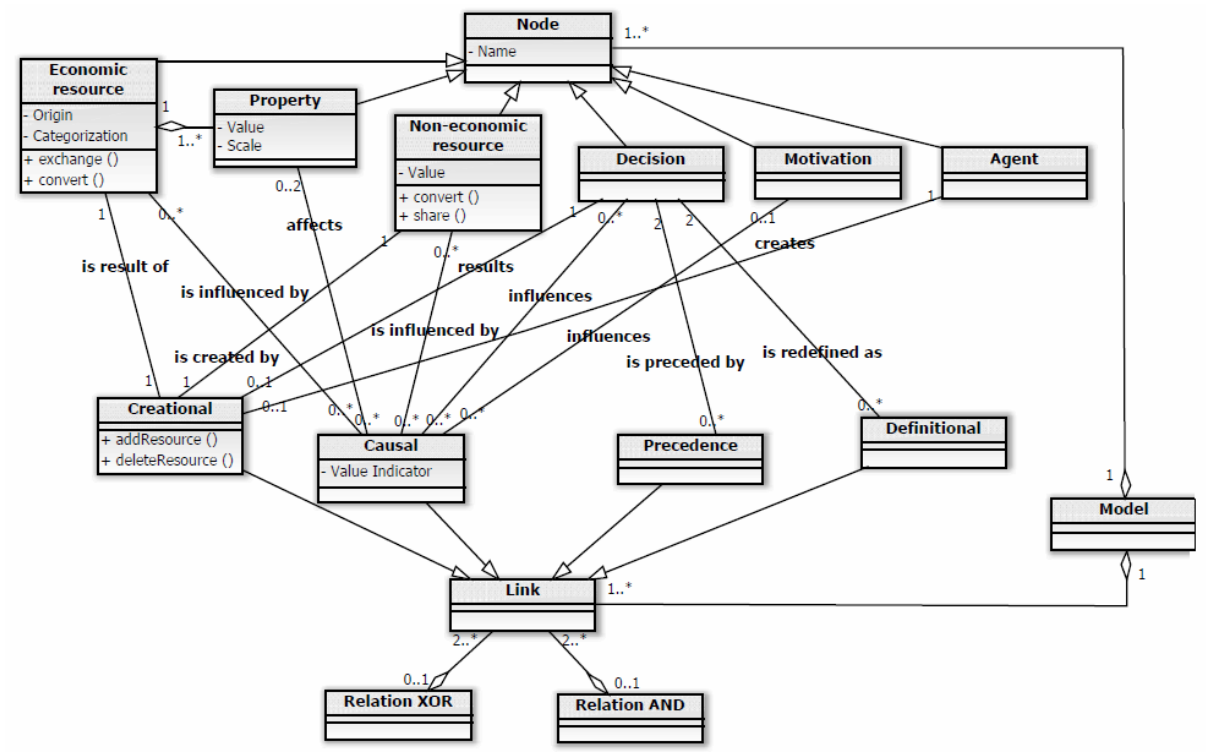

Fig. 2. The BBM meta-model

Table 2 presents the syntactically and semantically modified BBM. A number of changes from the original were done in order to improve it. In particular, the following items are of interest: new nodes for agent and motivation are introduced; 
Table 2. Syntax and semantics of BBM

\begin{tabular}{|c|c|c|}
\hline BBM Concept & Syntax & Semantic \\
\hline Agent & Circle & $\begin{array}{l}\text { Rational entity capable to achieve goals (resources) by } \\
\text { taking decisions based on motivations. }\end{array}$ \\
\hline $\begin{array}{l}\text { Economic } \\
\text { resource (noun) }\end{array}$ & $\begin{array}{l}\text { Dotted square } \\
\text { box }\end{array}$ & $\begin{array}{l}\text { Resources which are transferable (or convertible) and } \\
\text { valuable. They are described by a set of properties (at } \\
\text { least one). There are subcategories: goods, information, } \\
\text { services or money. }\end{array}$ \\
\hline $\begin{array}{l}\text { Economic } \\
\text { resource property } \\
\text { (adjective) }\end{array}$ & Rounded box & $\begin{array}{l}\text { Property of a resource evaluated on a qualitative or } \\
\text { quantitative scale (either positive or negative value). } \\
\text { Property concerns inner characteristics but also customer, } \\
\text { financial and infrastructural aspects. }\end{array}$ \\
\hline Categorization & Rectangle box & $\begin{array}{l}\text { Classification of the properties of an economic resource } \\
\text { in four perspectives: Customer, Financial, Infrastructure } \\
\text { and Value proposition. }\end{array}$ \\
\hline $\begin{array}{l}\text { Non-economic } \\
\text { resource }\end{array}$ & Diamond box & $\begin{array}{l}\text { Resources which are not transferable. They are } \\
\text { convertible or shared. They are concerning inner value } \\
\text { for the studied agent. }\end{array}$ \\
\hline Motivation & $\begin{array}{l}\text { Parallelogram } \\
\text { box }\end{array}$ & $\begin{array}{l}\text { Real reasons (either positive or negative) that the agent } \\
\text { possesses to achieve goals and means (either economic } \\
\text { or non-economic resources). }\end{array}$ \\
\hline Decision & Square box & $\begin{array}{l}\text { Decision nodes represent ways to achieve goals and } \\
\text { means. }\end{array}$ \\
\hline Precedence link & Arrow & $\begin{array}{l}\text { The information from the out-node decision is available } \\
\text { at the time the in-node decision is taken. It expresses } \\
\text { temporality: the change from one state to other state } \\
\text { depending on decisions that have been taken. }\end{array}$ \\
\hline Causal link & $\begin{array}{l}\text { Arrow with } \\
\text { value indicator }\end{array}$ & $\begin{array}{l}\text { Out-node has an impact in the in-node depending on the } \\
\text { value indicator. }\end{array}$ \\
\hline Definitional link & Empty arrow & $\begin{array}{l}\text { The connected nodes are decision nodes. The purpose is } \\
\text { to improve the definition of a decision by using sub- } \\
\text { decisions (which are more detailed). }\end{array}$ \\
\hline Creational link & Dotted links & $\begin{array}{l}\text { Both links are used to trace the reason why resources are } \\
\text { added or deleted. The reason is linked to a specific } \\
\text { decision. }\end{array}$ \\
\hline XOR-relation & $\begin{array}{l}\text { Bounded } \\
\text { connector }\end{array}$ & $\begin{array}{l}\text { A connector between links of same type. Those } \\
\text { connectors act as constraint on the nodes attached to the } \\
\text { links; at least one out-node have to be considered to grant } \\
\text { the consideration of the in-node but not all of them. }\end{array}$ \\
\hline AND-relation & $\begin{array}{l}\text { Double bounded } \\
\text { connector }\end{array}$ & $\begin{array}{l}\text { A connector between links of same type. Those } \\
\text { connectors act as constraint on the nodes attached to the } \\
\text { links; all out-nodes have to be considered to grant the } \\
\text { consideration of the in-node. }\end{array}$ \\
\hline \multicolumn{3}{|l|}{ Value indicator } \\
\hline Positive & + & Positive influence. \\
\hline Negative & - & Negative influence. \\
\hline
\end{tabular}

definitions for economic resource, economic resource properties, non-economic resource and decision are updated; and modifications in value indicator and creational link are introduced. For space reasons we did not include the graphical representations of the concepts; however, a sub set of them are used in figure 5. 
Table 3. Translation table between goal models ( $\left.{ }^{*}, \mathrm{BMM}, \mathrm{KAOS}\right)$, value models $\left(\mathrm{e}^{3}\right.$ value, $\mathrm{BMO}, \mathrm{REA})$, and the BBM

\begin{tabular}{|c|c|c|c|c|c|c|}
\hline$\overline{B B M}$ & $i^{*}$ & BMM & KAOS & $e^{3}$ value & BMO & REA \\
\hline \multicolumn{7}{|c|}{ NODES } \\
\hline Agent & Actor & $\begin{array}{l}\text { External } \\
\text { influencer }\end{array}$ & Agent & Actor & $\begin{array}{l}\text { Main } \\
\text { actor } \\
\text { Partners } \\
\text { Customers }\end{array}$ & $\begin{array}{l}\text { Economic } \\
\text { agent }\end{array}$ \\
\hline $\begin{array}{l}\text { Economic } \\
\text { resource }\end{array}$ & Resource & $\begin{array}{l}\text { Internal } \\
\text { influencer }\end{array}$ & Entity & $\begin{array}{l}\text { Value } \\
\text { object }\end{array}$ & $\begin{array}{l}\text { Resources } \\
\text { Costs } \\
\text { Revenues }\end{array}$ & $\begin{array}{l}\text { Economic } \\
\text { resource }\end{array}$ \\
\hline Origin & $\begin{array}{l}\text { Dependency } \\
\text { link }\end{array}$ & $\begin{array}{l}\text { External } \\
\text { influencer }\end{array}$ & & $\begin{array}{l}\text { Value } \\
\text { exchange }\end{array}$ & & \\
\hline Property & $\begin{array}{l}\text { Goal } \\
\text { Soft-goal }\end{array}$ & End: goal & Goal & & & \\
\hline \multicolumn{7}{|l|}{ Categorization } \\
\hline $\begin{array}{l}\text { Non-economic } \\
\text { resource }\end{array}$ & Soft-goal & & & & & \\
\hline Motivation & Goal & Ends & $\begin{array}{l}\text { Expectation } \\
\text { Goal }\end{array}$ & & & \\
\hline Decision & Task & Means & $\begin{array}{l}\text { Requirement } \\
\text { Operation } \\
\text { Event }\end{array}$ & $\begin{array}{l}\text { Value } \\
\text { activity } \\
\text { Start } \\
\text { stimulus }\end{array}$ & Activity & $\begin{array}{l}\text { Economic } \\
\text { event }\end{array}$ \\
\hline Causal & $\begin{array}{l}\text { Contribution } \\
\text { link } \\
\text { Dependency } \\
\text { link }\end{array}$ & $\begin{array}{l}\text { Links } \\
\text { among } \\
\text { nodes }\end{array}$ & NKS & $\begin{array}{l}\text { Value } \\
\text { exchange }\end{array}$ & $\begin{array}{l}\text { Links } \\
\text { among } \\
\text { nodes }\end{array}$ & $\begin{array}{l}\text { Links } \\
\text { among } \\
\text { nodes }\end{array}$ \\
\hline $\begin{array}{l}\text { Value } \\
\text { Indicator }\end{array}$ & $\begin{array}{l}\text { Contribution } \\
\text { indicator }\end{array}$ & Assessment & Obstacle & & & \\
\hline Precedence & & & & & & \\
\hline Definitional & Decomposition & & Refinement & & & \\
\hline $\begin{array}{l}\text { Creational } \\
\text { Suppressing }\end{array}$ & & & & & & \\
\hline
\end{tabular}

Methodology. The purpose of the methodology is to construct the BBM on the basis of other models, or vice versa. The methodology is composed of several methods. The modeler can commence work by eliciting motivations, decisions, or resources. Depending on the starting point and what the modeler wants to achieve, the methods differ.

Firstly, a translation table (table 3) provides the mapping of related concepts to clarify them to the modeler. The goal modeling languages considered are ${ }^{*}$, $\mathrm{BMM}$, and KAOS. The business modeling languages are $\mathrm{e}^{3}$ value, BMO, and REA. Note that the mapping table does not imply that we use a straight mapping between the goal layer and the business layer. The gaps in the table (empty cells) shows that we need another tool - the BBM model - to fix them and provide a consistent flow of information for the alignment work. 
Secondly, the methods of the methodology are altered. Here we illustrate one method ('start with a goal model, create a BBM, and end with an aligned value model') that is re-defined with the 'create the BBM' part outlined as follows:

- The first step is to identify the involved agents.

- For each agent, it is relevant to collect motivations, decisions and resources. The modeler can establish the relation between these concepts in several ways but we focus on a reformulated core idea from the Rational Agent theory: based on a motivation an agent takes a decision to exchange resource(s) with other agents in order to fulfill its intentions (Motivation - Decision - Resource).

- In the next step, the modeler defines the economic resources by means of their properties. It is optional to use the categorization element for further details.

- Afterward, the modeler starts to relate nodes using causal links. The value indicators on the causal links are added by a simple criterion: it helps, the modeler adds ' + '; or it hurts, the modeler adds ' - '. Note that, depending on the purpose of the model, there can be no ' + ' and '- 'simultaneously. The modeler must fix the analysis context and decide according to her/his understanding.

- Finally, the modeler refines the model by using creational, definitional or precedence links.

\section{Illustrative Case Study}

To illustrate the use of the BBM we include a (very) short case. It is a fraction of a case that we currently study. The case is based on [9] and revolves around the organization of a scientific conference.

"The Scientific Conference scenario (SC) is about organizing a scientific conference. For this purpose a set of activities have been arranged to acquire submissions, assign reviewers, decide on papers and organization of the conference. The business scenario involves four agents: program committee, steering committee, author and reviewer. The task of the program committee is to organize the conference. The authors send submissions to the program committee. The program committee assigns reviewers to each paper and sends papers for reviewing. The reviewers submit their review reports to the program committee. Upon receiving the review reports the program committee decides on acceptance of papers. The decision is sent to the authors together with evaluations. The program committee is responsible for providing the conference program. The steering committee is responsible for funding the conference."

The objective is to construct the BBM model from an instance of $\mathrm{i}^{*}$ goal model and derive an instance of $\mathrm{e}^{3}$ value business model from the BBM. After this, we reflect on the quality of the result.

Figure 3 shows an overview of the text description using the $i^{*}$ notation. It presents the boundary of each agent and the elements (goals, soft-goals, tasks and resources) that belong to each one. As prescribed the BBM the modeler has to develop one model for each agent's point of view. In this case, we focus on the program committee's. Figure 4 shows the scenario for the program committee. We observe that the main goal is 'Organize a quality SC', that is, a popular conference. It means to attain 

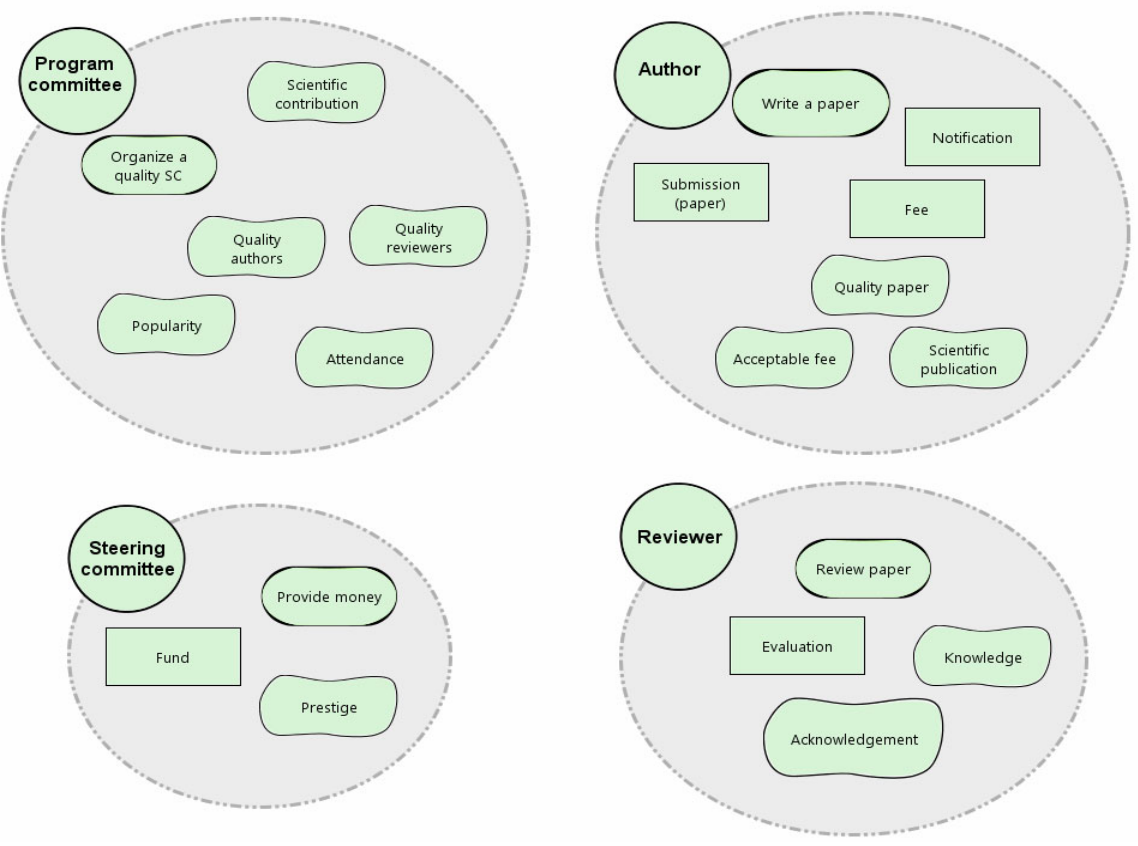

Fig. 3. $i^{*}$ model (strategic dependency) for the case (general overview)

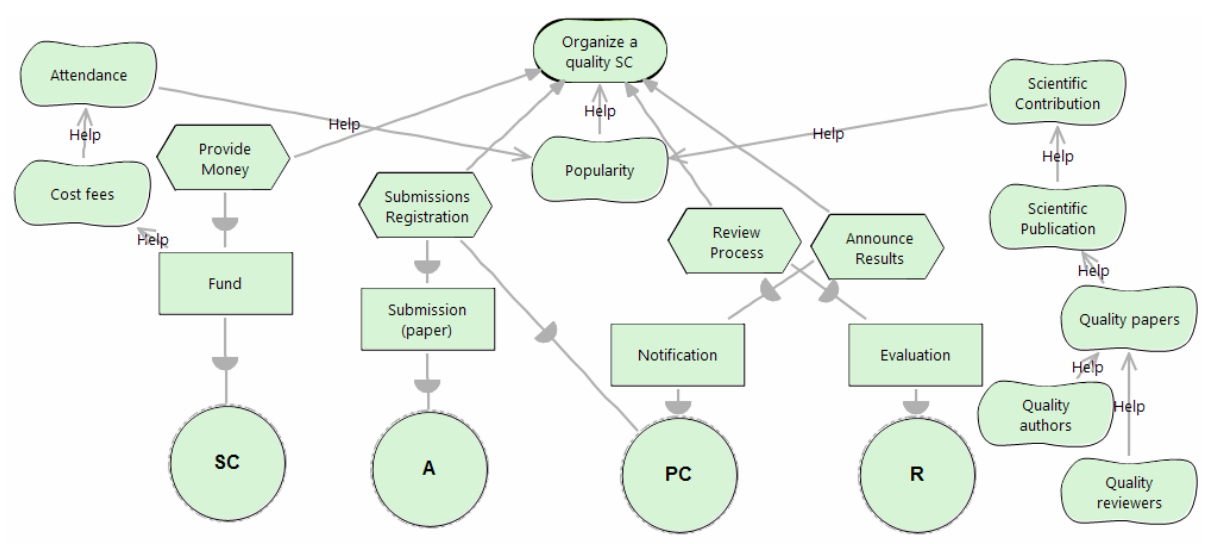

Fig. 4. i model (rationale dependency) for the case (program committee's view)

high popularity by means of high attendance and significant scientific contributions. The attendance depends on the costs of the fees and the scientific contributions on the quality of the papers that have been submitted.

According to figures 3 and 4, we follow the described method and obtain the BBM model shown in figure 5 . 


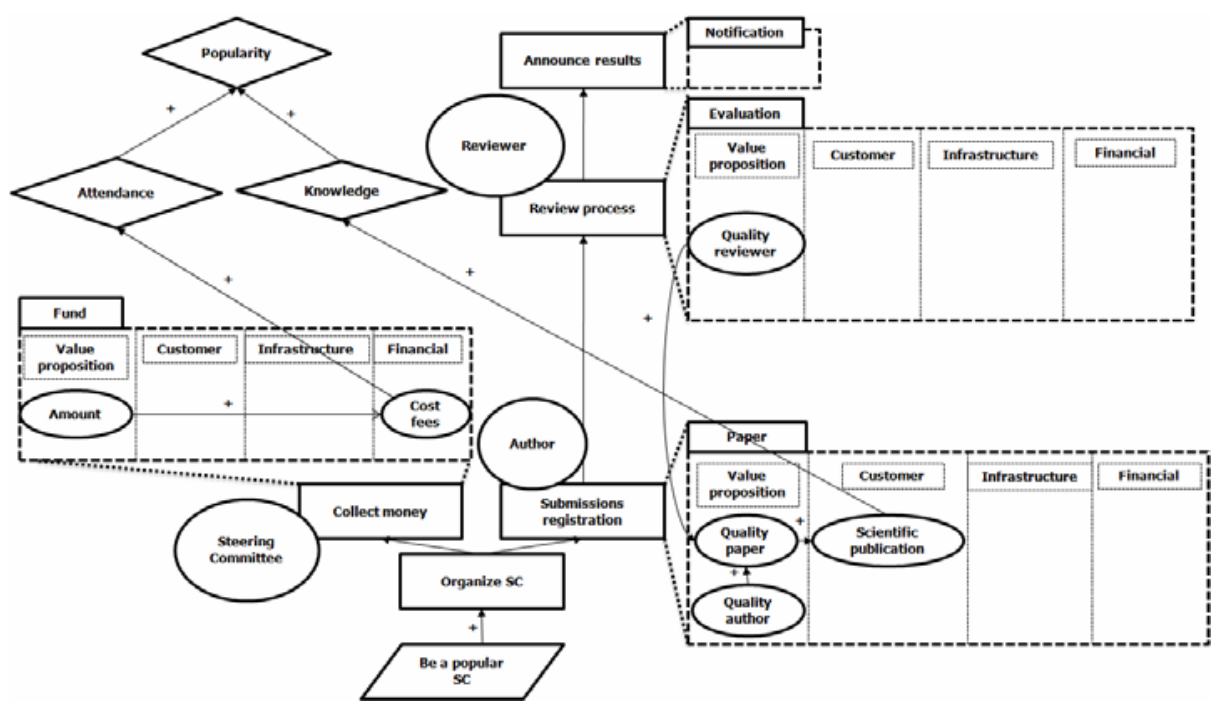

Fig. 5. BBM model for the case by using the new approach (program committee's view)

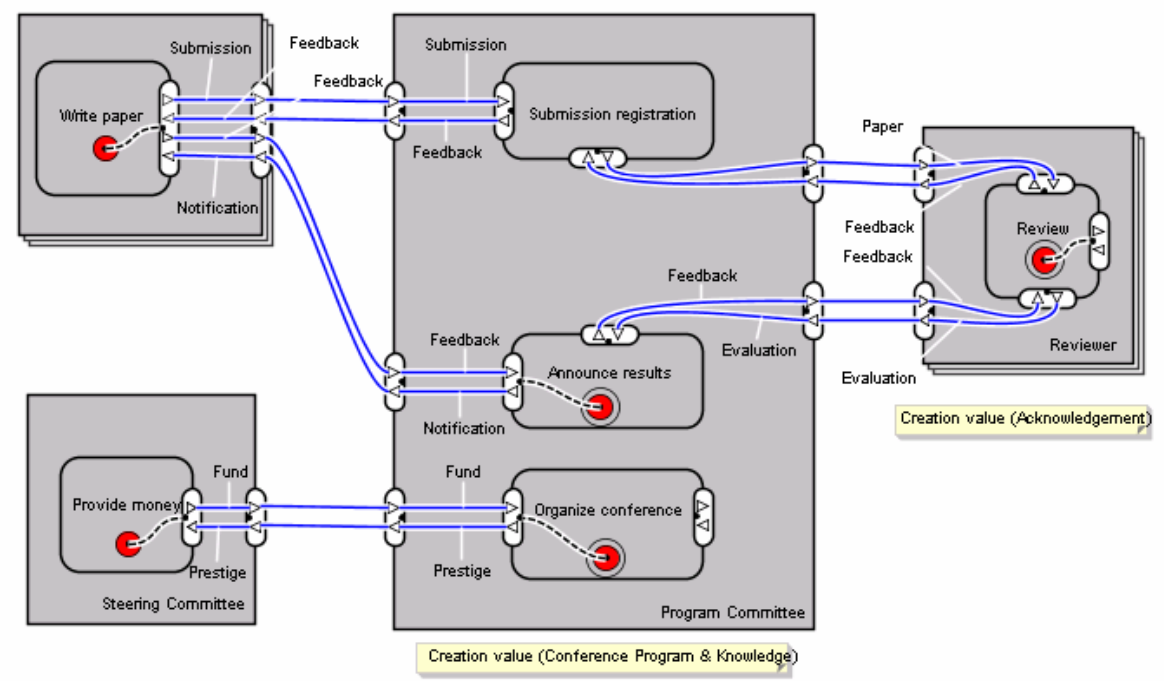

Fig. 6. $\mathrm{e}^{3}$ value model for the case (program committee's view)

Figure 5 starts from the motivation of 'Be a popular SC'. To obtain popularity, it drives to take the decision of organizing a scientific conference. This decision splits into two sub-decisions: 'Collect money' (interacting with Steering Committee) and 'Submissions registration' (interacting with Author). A submission registration creates a resource 'Paper' that has some properties. Reviewers should review papers and select the better ones. Finally, the program committee announces the results to the 
authors. Note that one property can affect (positive or negative) another property. In this example, attendance is influenced by the costs of the fees and knowledge (scientific contribution) by the quality of the papers. Both attendance and knowledge affect to the popularity. It is important to notice that decisions can include a communication with external agents by adding a circle beside the decision. These communications are translated in exchanges of resources between agents in value models. Figure 6 shows an example using $\mathrm{e}^{3}$ value notation.

Compared to the original version of the BBM presented in [16] we are now in the position to make a better alignment work. I.e., we claim that the $\mathrm{e}^{3}$ value model in figure 6 is of higher quality than what it would have been should we have used the original BBM. As we now have a better understanding of agent motivations, we clearly can describe the goals of the PC and understand what resources it will exchange with other agents in order to attain those goals. In particular, we are able to describe how properties of resources help or hinder in goal attainment. Another improvement is that, by incorporating the agent construct in the BBM, this information can be used directly when constructing the business model.

\section{Concluding Discussion and Future Work}

In this paper we have revised the initial proposal of the BBM for the purpose of making it more useful in the business/IT-alignment context. While the main ideas remain, we have introduced new features in its meta-model, syntax, semantics, and methodology. The most important contribution is that we have considered the concepts of agent and motivation. This way managers can make more supported decisions by means of being able to model the whole business collaboration, that is, why are they taking these decisions (both internal and external reasons), who is participating in it (competitors and partners), and what is the benefit of it (strategic resources). So, we provide a tool to help the decision making process and, in consequence, align the goal and business layers.

Future research directions include more validations. This means testing it on real cases and more deeply in each case. Another research direction, which will be worked on, is the methodology. In this paper we report on a method that starts with goals and arrives at resource exchanges (via decisions). Another method approach is to start by looking at what resources are available for an agent and formulate goals based on this availability. For this, the meta-model and the methodology need to be complemented in several ways.

\section{References}

1. Chan, Y.E., Reich, B.H.: IT alignment: what have we learned? Journal of Information Technology 22, 297-315 (2007)

2. Luftman, J., Kempaiah, R.: An Update on Business-IT Alignment: “A Line” Has Been Drawn. MIS Quarterly Executive 6(3), 165-177 (2007)

3. van Lamsweerde, A.: Goal-oriented requirements engineering: A guided tour. In: Proc. International Joint Conference on Requirements Engineering (RE 2001), pp. 249-263. IEEE, Los Alamitos (2001) 
4. Business Motivation Model (BMM), v.1.1. Object Management Group (OMG), http : / /www. omg.org/spec/BMM/1.1/

5. Yu, E.: Modelling Strategic Relationships for Process Reengineering, PhD thesis, University of Toronto, Department of Computer Science (1995)

6. Van der Aalst, W.: Formalization and Verification of Event-driven Process Chains. Information and Software Technology 41(10), 639-650 (1999)

7. Van der Aalst, W.: Petri Nets. Encyclopedia of Database Systems Part 16, 2103-2108 (2009)

8. BPMN Information Home Page, http: / / www . bpmn . org /

9. Edirisuriya, A.: Design Support for e-Commerce Information Systems using Goal, Business and Process Modelling. Doctoral Thesis, Stockholm University (2009)

10. Ilayperuma, T.: Improving E-business Design through Business Model Analysis. Doctoral Thesis, Stockholm University (2010)

11. Andersson, B., et al.: Enterprise Sustainability through the Alignment of Goal Models and Business Models. In: Proc. BUSITAL 2008, Montpellier, France (2008)

12. Osterwalder, A., Pigneur, Y.: An e-Business Model Ontology for Modeling e-Business. In: 15th Bled Electronic Commerce Conference e-Reality: Constructing the e-Economy (2002)

13. Gordijn, J., Yu, E., Van der Bas, R.: E-Service Design Using i* and e3value Modeling. IEEE Software 23(3), 26-33 (2006)

14. McCarthy, W.E.: The REA Accounting Model: A Generalized Framework for Accounting Systems in a Shared Data Environment. The Accounting Review (1982)

15. Lemaire, D., Andersson, B.: The Business Behavior Model. In: 5th International Workshop on Business/IT Alignment and Interoperability (BUSITAL 2010), Tunisia (2010)

16. Lemaire, D.: The Business Behavior Model: Concepts and Usages. Master's Thesis in Computer and Systems Sciences at Stockholm University (2010)

17. Bleistein, S.J., et al.: Validating strategic alignment of organizational IT using goal modeling and problem diagrams. Journal of Systems and Software 79, 362-378 (2006)

18. Nurcan, S., Rolland, C.: A multi-method for defining the organizational change. Information and Software Technology 45(2), 61-82 (2003)

19. Rao, A.S., Georgeff, M.P.: BDI-Agents: From Theory to Practice. In: 1st International Conference on Multiagent Systems, ICMAS 1995 , San francisco (1995)

20. Wernerfelt, B.: The Resource-Based View of the Firm. Strategic Management Journal 5(2), 171-180 (1984)

21. Barney, J.: Firm Resources and Sustained Competitive Advantage. Journal of Management 17(1), 99-120 (1991)

22. Osterwalder, A.: The Business Model Ontology: A Proposition in a Design Science Approach. HEC de l'Université de Lausanne (2004)

23. Gammelgård, M., et al.: Business Value Evaluation of IT Systems: Developing a Functional Reference Model. In: Conference on Systems Engineering Research, Los Angeles (2006) 